\title{
ANTIDIABETIC POTENTIAL OF PERILLYL ALCOHOL, A MONOTERPENE ON HIGH-FAT DIET LOW-DOSE STREPTOZOTOCIN-INDUCED DIABETES IN EXPERIMENTAL RATS
}

\author{
TOWSEEF HASSAN, ELANCHEZHIYAN C*, INSHA NASEER
}

Department of Zoology, Annamalai University, Chidambaram, Tamil Nadu, India. Email: chezhiyan6@gmail.com

Received: 25 June 2019, Revised and Accepted: 27 July 2019

\begin{abstract}
Objective: The aim of the study was to evaluate the antidiabetic potential of Perillyl alcohol (POH) in high-fat diet (HFD) and low-dose streptozotocin (STZ)-induced diabetic Wistar rats.

Methods: In experimental rats fed with HFD for 4 weeks, diabetes was induced by single intraperitoneal injection of STZ (35 mg/kg body weight [BW]). Three days after STZ induction, the hyperglycemic rats were treated with POH orally at the doses of 50 and $100 \mathrm{mg} / \mathrm{kg}$ BW daily for 30 days. Glibenclamide (6 mg/kg BW) was used as reference drug. Blood glucose level, BW, fluid intake, and food intake such as parameters were analyzed throughout the experiment period. Serum and plasma biochemical parameters were also estimated. Assay on insulin resistance was also done. Histological study of the pancreas and liver was also performed.
\end{abstract}

Results: POH orally at the doses of 50 and $100 \mathrm{mg} / \mathrm{kg}$ BW for 30 days significantly $(\mathrm{p}<0.05)$ and dose-dependently reduced and normalized blood glucose levels as compared to that of HFD+STZ control group. Serum and plasma parameters were significantly (p<0.05) restored toward the normal levels in POH-treated rats as compared to HFD-STZ control animals. Histological study of liver and pancreas also shows the prominent regeneration in $\mathrm{POH}$ and glibenclamide treated rats.

Conclusion: The present study concludes that POH demonstrated promising antidiabetic action in HFD STZ-induced diabetic rats.

Keywords: Diabetes, Glibenclamide, Hypoglycemic, Streptozotocin, Perillyl alcohol, High-fat diet.

(C) 2019 The Authors. Published by Innovare Academic Sciences Pvt Ltd. This is an open access article under the CC BY license (http://creativecommons. org/licenses/by/4. 0/) DOI: http://dx.doi.org/10.22159/ajpcr.2019.v12i9.34698

\section{INTRODUCTION}

Diabetes is a complex multisystemic disorder characterized by a relative or absolute insufficiency of insulin secretion and disturbances in carbohydrate, protein, and lipid metabolism [1]. The worldwide prevalence of diabetes almost in all countries has continued to increase severely. According to the International Diabetes Federation $8^{\text {th }}$ edition, the number of persons with diabetes in 2017 crossed 422 million, and by 2040 , this will rise up to 642 million [2]. Obesity the main cause of insulin resistance in Type 2 diabetes (T2D) new article is a complex, multifactorial, and largely preventable disease, affecting along with overweight, over one-third of the world's population today. Obesity increases risk of chronic diseases, namely, disability, depression, T2D, cardiovascular diseases, certain cancers, and mortality [3]. Recent studies observed that there is a link between obesity and Type 2 Diabetes by involving these processes such as, pro-inflammatory cytokines, deranged fatty acid metabolism, insulin resistance in which body cells didn't recognize the insulin and also leads to mitochondrial dysfunction and endoplasmic reticulum stress [4]. Obesity is one of the main causes of T2D mellitus (T2DM); many researches show that 60$90 \%$ of all patients with T2DM is or has been obese. Obesity is generally considered to be a very strong risk factor for the later development of T2DM [5]. Therapies currently available for diabetes include oral hypoglycemic agents such as glibenclamide, glipizide, gliclazide, nateglinide, repaglinide, acarbose, miglitol, dipeptidyl peptidase, sitagliptin, linagliptin, alogliptin, dutogliptin, gemigliptin, and injectable insulin but they have their own limitations due to selective mechanism of action [6]. Nowadays, interest is growing toward the use of natural phytochemicals for antidiabetic activity to keep the side effects of synthetic antidiabetic drugs away [7]. Research has shown that the plants contain a large variety of antioxidants in their substances [8]. They can prevent the formation of advanced glycated end products and other diabetic complications associated with oxidative stress [9].
Perillyl alcohol (POH) (Fig. 1) is a naturally occurring monocyclic monoterpene that can be purified from various plants such as peppermint, spearmint, cherries, and celery [10]. It has been shown by many researches that $\mathrm{POH}$ possesses significant antioxidant, antitumor, anti-inflammatory, and antifungal activity in vivo as well as in vitro [10-12]. Conventionally, $\mathrm{POH}$ is used for many households and other ingredients for cleaning products, fragrance in toiletries and for the cosmetics $[13,14]$. It is permitted by the U.S. Food and Drug Administration (FDA) as food additives, primarily for the purpose of flavoring agents [15]. However, the antidiabetic effect of POH in STZ induced diabetes in Wistar rats is still elusive.

\section{METHODS}

Animals

Healthy male albino Wistar rats (160-180 g) were obtained from Biogen Laboratory Animal Facility, Bengaluru, India, and maintained at a constant temperature $\left(25 \pm 1^{\circ} \mathrm{C}\right)$ on a $12 \mathrm{~h}$ light/12 h dark cycle with standard pellet diet (National Institute for Nutrition, Hyderabad, India) and water was provided ad libitum. The study was approved by the Institutional Animal Ethics Committee of Rajah Muthiah Medical College (Reg no. 160/PO/ReBi/S/1999/CPCSEA, Proposal no. 1192), Annamalai University.

\section{Chemicals}

$\mathrm{POH}$ and streptozotocin (STZ) were purchased from Sigma-Aldrich (St. Louis, MO, USA) and other chemicals were obtained from E. Merck, HiMedia (Mumbai India). All of the chemicals and reagents used in these experiments were analytical grade.

\section{High-fat diet (HFD) fed STZ-induced diabetes}

The rats were divided into two dietary regimens by feeding either normal diet or HFD for the initial period of 4 weeks as done by 
Magdalena et al. [16]. The composition (Table 1) and preparation of HFD are shown below (58\% fat, $25 \%$ protein, and $17 \%$ carbohydrate, as a percentage of total kcal has been described earlier [17]. After 4 weeks of dietary manipulation, the groups of rats fed with HFD were injected intraperitoneally with a low dose of ST $35 \mathrm{mg} / \mathrm{kg}$ $\mathrm{BW}$ ) dissolved in $0.1 \mathrm{M}$ cold citrate buffer, $\mathrm{pH}$ 4.5. Three days after intraperitoneally STZ injection, the rats were screened for blood glucose level. Rats having fasting blood glucose (FBG) $>250 \mathrm{mg} / \mathrm{dl}$ that exhibited random hyperglycemia were selected for the experiment.

\section{Experimental design}

A total number of 30 rats were divided into five groups of six animals each (six normal rats and 24 diabetic rats). Saline was used as vehicle. $\mathrm{POH}$ and glibenclamide were dissolved in saline and administered orally once in a day for 30 days.

Group 1 - Normal rats treated with vehicle alone.

Group 2 - HFD fed STZ-induced experimental diabetic rats ( $35 \mathrm{mg} / \mathrm{kg}$ BW). Group 3 - HFD fed STZ-induced diabetic rats orally treated with $\mathrm{POH}$ ( $50 \mathrm{mg} / \mathrm{kg} \mathrm{BW} /$ day for 30 days).

Group 4 - HFD fed STZ-induced diabetic rats orally treated with POH (100 mg/kg BW/day for 30 days)

Group 5 - HFD fed STZ-induced diabetic rats orally treated with glibenclamide ( $6 \mathrm{mg} / \mathrm{kg} \mathrm{BW} /$ day for 30 days).

During the experimental period, body weight (BW), food and water consumption, and physical examinations were determined at regular

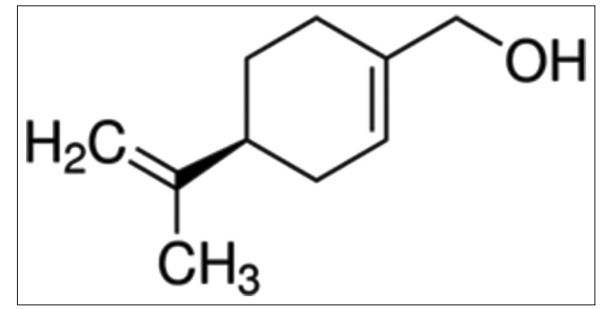

Fig. 1: Structure of Perillyl alcohol $\left(\mathrm{C}_{10} \mathrm{H}_{16} \mathrm{O}\right)$

Table 1: Composition of high-fat diet

\begin{tabular}{ll}
\hline Ingredients & Diet (g/100 g) \\
\hline Powdered NPD & 36.5 \\
Lard & 31 \\
Casein & 25 \\
Cholesterol & 1 \\
Sodium cholate & 0.5 \\
Vitamin mineral mix & 6 \\
dl-Methionine & 0.3 \\
Yeast powder & 0.1 \\
Sodium chloride & 0.1 \\
\hline
\end{tabular}

*The composition of normal pellet diet (NPD): $4.1 \%$ fat, $22.2 \%$ protein, and

$12.1 \%$ carbohydrates, as a percentage of total kilocal intervals. At the end of the treatment period, the rats were fasted overnight and sacrificed by cervical decapitation. The blood was collected with and without anticoagulants for plasma and serum separation, respectively.

\section{Oral glucose tolerance test (OGTT)}

After 30 days of intragastric administration, the 12-h-fasted rats in all groups were intragastrically administered glucose $(2.0 \mathrm{~g} / \mathrm{kg})[18]$. Blood samples were obtained at $0,30,60$, and $120 \mathrm{~min}$ after glucose administration. The FBG levels were immediately estimated using the blood glucometer (Fig. 2).

\section{Histopathological studies}

The liver and pancreas tissues were fixed in 10\% formalin for $48 \mathrm{~h}$. It was then followed by dehydration by passing through a series of graded alcohol, beginning with $50 \%$ alcohol and progressing in graded step to $100 \%$ (absolute) alcohol and was finally embedded in paraffin. Sections of the liver (5-6 $\mu \mathrm{m}$ thick) were developed using semi-automated rotator microtome, stained with Hematoxylin and Eosin dye and observed microscopically [19].

\section{Assay on insulin resistance}

The insulin resistance developed in the experimental animals (Fig. 3) was evaluated by a homeostasis model of insulin resistance (HOMA-IR). The HOMA-IR was calculated by the method of Bhandari et al., 2013 [20], as follows:

$$
\text { HOMA }-\mathrm{IR}=\frac{\begin{array}{c}
\text { Fasting insulin level }(\mu \mathrm{U} / \mathrm{ml}) \times \\
\text { Fasting blood glucose }(\mathrm{mg} / \mathrm{dl})
\end{array}}{405}
$$

\section{Biochemical estimations}

Glucose was estimated using the method of Trinder using a reagent kit [21]. Hemoglobin was estimated using the method of Drabkin and Austin [22]. Glycosylated hemoglobin was estimated using the method of Bannon [23]. Plasma insulin was assayed by ELISA method using Boehringer Mannheim kit (Boehringer analyzer ES 300). Glycogen content in the liver and skeletal muscle was estimated by the method of Morales et al. [24].

\section{Statistical analysis}

All values are expressed as mean \pm standard deviation for six rats in each group. One-way ANOVA followed by Duncan's multiple range test using IBM SPSS version 22. Statistical significance was compared within the groups as follows: ${ }^{a}$ Control rats; ${ }^{b}$ diabetic control rats. Values are statistically significant at ${ }^{*} \mathrm{p}<0.05$.

\section{RESULTS}

Effect of POH on changes in BW, food, and fluid intake in control and diabetic treated rats

Table 2 shows the changes in the BW of control and diabetic treated rats. The initial BWs of rats were almost similar in all groups. When rats were fed with HFD for 4 weeks, the BW of rats in groups 2-5 was

Table 2: Effect of POH on BW of normal control and HFD/STZ-induced diabetic treated rats

\begin{tabular}{lll}
\hline Groups & BW (g) (week) & \\
\cline { 2 - 3 } & $\mathbf{0}$ & $\mathbf{4}$ \\
\hline Normal control & $175.03 \pm 12.38$ & $182.09 \pm 12.39$ \\
Diabetic (HFD+STZ) & $176.07 \pm 11.71^{\mathrm{a}}$ & $258.13 \pm 19.14^{\mathrm{a} *}$ \\
Diabetic+POH (50 mg/kg BW) & $174.09 \pm 12.31^{\mathrm{b}}$ & $257.14 \pm 17.78^{\mathrm{b}}$ \\
Diabetic+POH (50 mg/kg BW) & $177.73 \pm 12.63^{\mathrm{b}}$ & $259.93 \pm 17.77^{\mathrm{b}}$ \\
Diabetic+Glibenclamide (6 mg/kg BW) & $175.64 \pm 12.61^{\mathrm{b}}$ & $256.23 \pm 17.31^{\mathrm{b}}$ \\
\hline
\end{tabular}

POH: Perillyl alcohol, BW: Bodyweight, HFD: High-fat diet, STZ: Streptozotocin. Values are expressed as means \pm standard deviation for six rats in each group. One-way ANOVA followed by Duncan's multiple range test. Statistical significance was compared within the groups as follows: aControl rats; bdiabetic control rats. Values are statistically significant at $* \mathrm{p}<0.05$ 
significantly increased. At the end of the experimental period, the BW was significantly decreased in diabetic rats when compared to normal control rats. Similarly, Figs. 4 and 5 show that food and fluid intake was significantly elevated in diabetic rats throughout the experimental period. Oral administration of $\mathrm{POH}$ dose-dependently for 30 days to diabetic rats significantly decreased food and fluid intake with improvement in BW. These results were compared with diabetic control group.

\section{Effect of $\mathrm{POH}$ on blood glucose}

On induction of diabetes using HFD and STZ resulted in the increase of blood glucose in all the diabetic group animals. High FBG is one of the important indicators of diabetes. In the non-diabetic control group, the blood glucose remained normal. In diabetes-induced groups, treatment with $\mathrm{POH}$ (50 and $100 \mathrm{mg} / \mathrm{kg} \mathrm{BW}$ ) significantly decreased the level of blood glucose, as compared to the disease control $(\mathrm{p}<0.05)$. The standard glibenclamide treated group animals also showed the reduction of blood glucose (Table 3 ).

Effect of $\mathrm{POH}$ on plasma insulin

The effect of $\mathrm{POH}$ on plasma insulin was analyzed (Table 3). $\mathrm{POH}$ treated group animals showed a significant increase in the level of

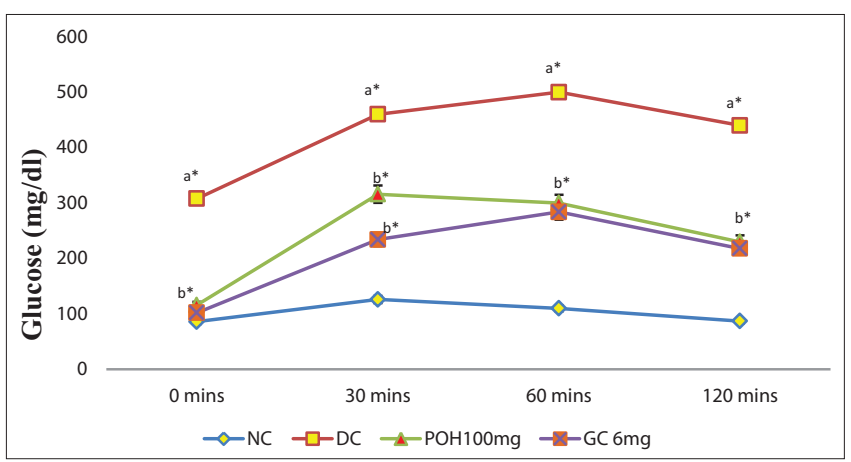

Fig. 2: Effect of Perillyl alcohol on oral glucose tolerance test on normal control and high-fat diet/streptozotocin (HFD/ STZ)-induced diabetic treated rats. Statistical significance was compared within the groups as follows: ${ }^{a}$ Control rats; ${ }^{\text {bdiabetic }}$ control rats. Values are statistically significant at ${ }^{*} \mathbf{p}<0.05$. NC: Normal control; DC: Diabetic (HFD+STZ); Perillyl alcohol 100: Diabetic+Perillyl alcohol 100 mg/kg; GC: Diabetic+Glibenclamide

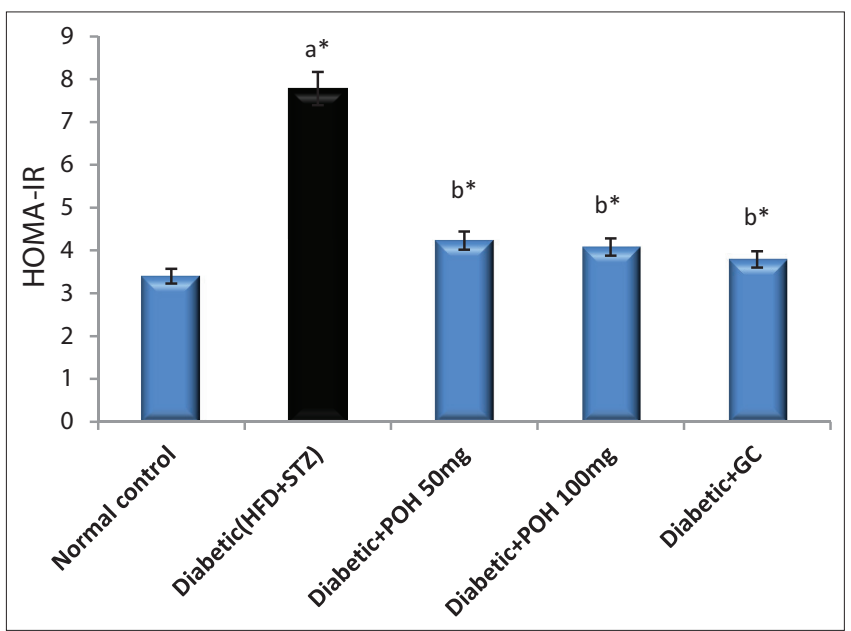

Fig. 3: Effect of Perillyl alcohol on Homeostatic Model Assessment of Insulin Resistance. Bars are expressed as means \pm standard deviation for six rats in each group. One-way ANOVA followed by Duncan's multiple range test (DMRT). Statistical significance was compared within the groups as follows: aControl rats; ${ }^{b}$ diabetic control rats. Values are statistically significant at $* \mathbf{p}<0.05$ plasma insulin $(\mathrm{p}<0.05)$. At the end of the study, the insulin content was decreased in the disease control group. On 30 days of treatment, the glibenclamide, $\mathrm{POH}$ showed a significant increase in the level of plasma insulin $(\mathrm{p}<0.05)$.

Effect of $\mathrm{POH}$ on $\mathrm{Hb}$ and $\mathrm{HbA1c}$ levels in experimental rats

A decrease in $\mathrm{Hb}$ with a significant increase in HbA1c levels was observed in HFD low-dose STZ-induced diabetic rats compared to normal control rats (Fig. 6). Oral administration of $\mathrm{POH}(50$ and $100 \mathrm{mg} / \mathrm{kg} \mathrm{BW}$ ) for 30 days to diabetic rats significantly reversed their levels to near normal.

Effect of $\mathrm{POH}$ on liver and skeletal muscle glycogen

The effect of POH on liver and muscle glycogen was analyzed (Table 4). $\mathrm{POH}$ treated group animals showed a significant increase in the level of liver and skeletal muscle glycogen $(\mathrm{p}<0.05)$. At the end of the study, the liver and skeletal muscle glycogen content was decreased in the disease control group. On 30 days of treatment, the glibenclamide, $\mathrm{POH}$ showed significant increase in the level of liver and muscle glycogen $(\mathrm{p}<0.05)$.

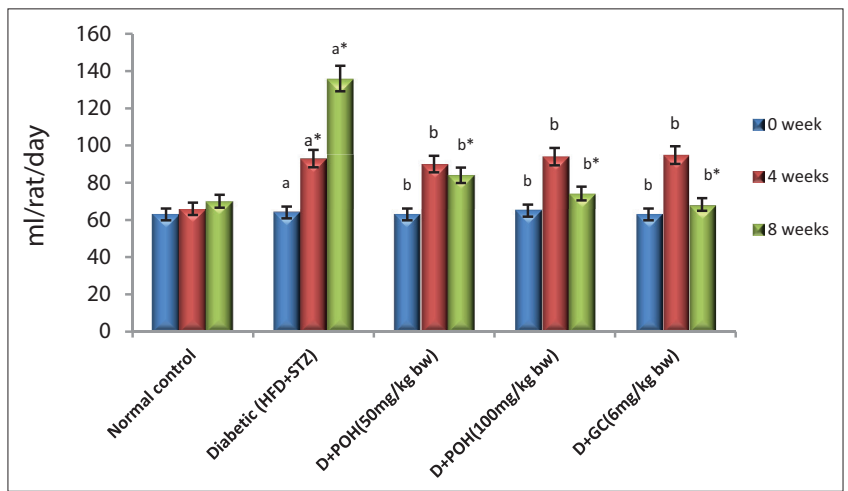

Fig. 4: Effect of Perillyl alcohol on fluid intake of normal control and high-fat diet/streptozotocin-induced diabetic treated rats.

Bars are expressed as means \pm standard deviation for six rats in each group. One-way ANOVA followed by Duncan's multiple range test. Statistical significance was compared within the

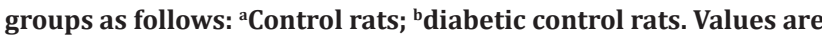
statistically significant at ${ }^{*} \mathbf{p}<0.05$

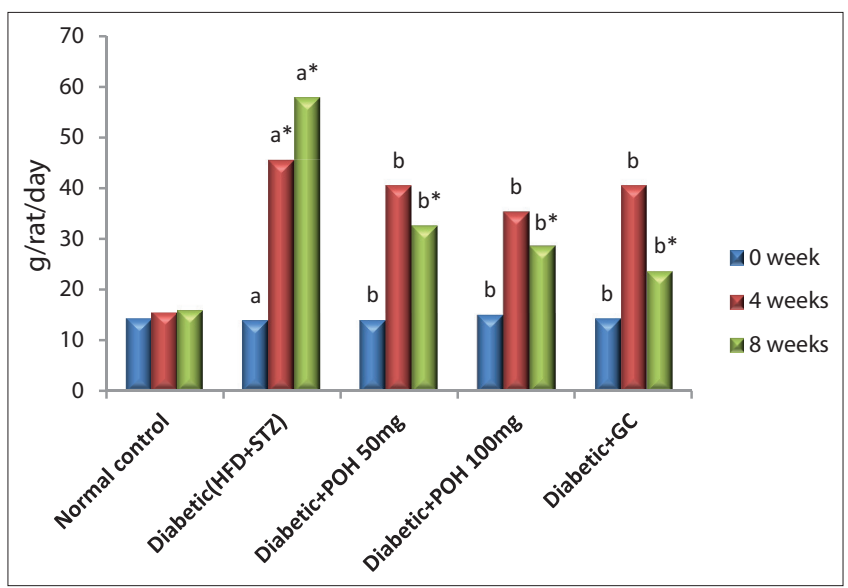

Fig. 5: Effect of Perillyl alcohol on food intake of normal control and high-fat diet/streptozotocin-induced diabetic treated rats. Bars are expressed as means \pm standard deviation for six rats in each group. One-way ANOVA followed by Duncan's multiple range test. Statistical significance was compared within the

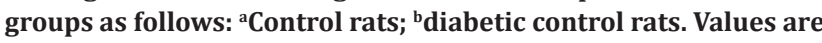
statistically significant at $* p<0.05$ 
Table 3: Effect of POH on blood glucose, insulin, Hb, and HbA1c in normal and HFD-STZ-induced diabetic rats

\begin{tabular}{|c|c|c|c|c|}
\hline Groups & Glucose (mg/dl) & Insulin $(\mu \mathrm{U} / \mathrm{ml})$ & $\mathrm{Hb}(\mathrm{mg} / \mathrm{dl})$ & HbA1c (mg/dl) \\
\hline Normal control & $86.00 \pm 6.64$ & $16.08 \pm 1.21$ & $12.18 \pm 1.67$ & $0.41 \pm 0.02$ \\
\hline Diabetic (HFD+STZ) & $308.99 \pm 12.17^{a *}$ & $10.18 \pm 0.24^{\mathrm{a} *}$ & $6.23 \pm 1.03^{\mathrm{a} *}$ & $1.12 \pm 0.09^{\mathrm{a} *}$ \\
\hline Diabetic+POH (50 mg/kg BW) & $128.99 \pm 9.96^{\mathrm{b} *}$ & $13.24 \pm 1.04^{\mathrm{b} *}$ & $10.13 \pm 1.39^{\mathrm{b} *}$ & $0.60 \pm 0.05^{\mathrm{b} *}$ \\
\hline Diabetic+POH (50 mg/kg BW) & $116.99 \pm 9.95^{\mathrm{b} *}$ & $14.15 \pm 1.12^{\mathrm{b} *}$ & $11.48 \pm 0.94^{\mathrm{b} *}$ & $0.59 \pm 0.05^{\mathrm{b} *}$ \\
\hline Diabetic+Glibenclamide (6 mg/kg BW) & $102.02 \pm 8.85^{\mathrm{b} *}$ & $15.08 \pm 1.66^{\mathrm{b} *}$ & $12.00 \pm 0.12^{\mathrm{b} *}$ & $0.47 \pm 0.04^{\mathrm{b} *}$ \\
\hline
\end{tabular}

POH: Perillyl alcohol, BW: Bodyweight, HFD: High-fat diet, STZ: Streptozotocin. Values are expressed as means \pm standard deviation for six rats in each group. One-way

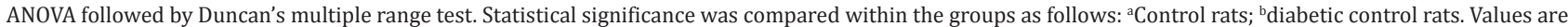
statistically significant at * $\mathrm{p}<0.05$. Hb: Hemoglobin; HbA1c: Glycosylated hemoglobin

Table 4: Effect of $\mathrm{POH}$ on liver and skeletal muscle glycogen in normal and HFD STZ-induced diabetic rats

\begin{tabular}{|c|c|c|}
\hline Groups & $\begin{array}{l}\text { Liver } \\
\text { glycogen (mg/g) }\end{array}$ & $\begin{array}{l}\text { Skeletal muscle } \\
\text { glycogen (mg/g) }\end{array}$ \\
\hline Normal control & $45.31 \pm 1.26$ & $1.87 \pm 0.14$ \\
\hline Diabetic (HFD+STZ) & $20.13 \pm 2.37^{a *}$ & $0.96 \pm 23.60^{\mathrm{a} *}$ \\
\hline Diabetic+POH & $38.23 \pm 2.37^{\mathrm{b} *}$ & $1.15 \pm 28.60^{\mathrm{b} *}$ \\
\hline$(50 \mathrm{mg} / \mathrm{kg} \mathrm{BW})$ & & \\
\hline Diabetic+POH & $40.18 \pm 3.79^{b *}$ & $1.43 \pm 25.60^{\mathrm{b} *}$ \\
\hline (50 mg/kg BW) & & \\
\hline $\begin{array}{l}\text { Diabetic+Glibenclamide } \\
(6 \mathrm{mg} / \mathrm{kg} \mathrm{BW})\end{array}$ & $43.10 \pm 4.55^{\mathrm{b} *}$ & $1.68 \pm 26.60^{\mathrm{b} *}$ \\
\hline \multicolumn{3}{|c|}{$\begin{array}{l}\text { POH: Perillyl alcohol, BW: Bodyweight, HFD: High-fat diet, STZ: Streptozotocin. } \\
\text { Values are expressed as means } \pm \text { standard deviation for six rats in each } \\
\text { group. One-way ANOVA followed by Duncan's multiple range test. Statistical } \\
\text { significance was compared within the groups as follows: }{ }^{a} \text { Control rats; }{ }^{b} \text { diabetic } \\
\text { control rats. Values are statistically significant at }{ }^{*} p<0.05\end{array}$} \\
\hline
\end{tabular}

Histological analysis of pancreas and liver samples

The histopathological observation of the pancreas (Fig. 7) reveals that the pancreatic islets of the disease animal were degenerated, with their cell size being shrunken and reduced islets of pancreas was observed. In normal control group, the cells appeared normal and being proliferated. Treatment with glibenclamide, POH $50 \mathrm{mg} / \mathrm{kg}$ bodyweight, and $100 \mathrm{mg} / \mathrm{kg}$ bodyweight has recovered the islets from degeneration and also enhanced the ability of the islet cells to proliferate. In the diabetic control liver histopathology, the hepatic cells were swollen, with spotty necrosis with the accumulation of lipids was observed. In normal control group, the animals were free from the impact of the disease, as the proper arrangement of the hepatic cells. The treatment group animals (glibenclamide $6 \mathrm{mg} / \mathrm{kg}$, POH $50 \mathrm{mg} / \mathrm{kg}$, and $100 \mathrm{mg} / \mathrm{kg}$ BW) showed that the cells were normal, devoid of necrosis with proper arrangement was observed. The fat accumulation was reduced in the treated group liver tissue (Fig. 8).

\section{DISCUSSION}

The HFD STZ-induced diabetic rat is one of the animal models of human non-insulin dependent diabetes mellitus (DM) or T2DM. As in human T2DM, diet plays a major role in the development of diabetes as well as hypertension, hyperlipidemia, and eventually kidney damage in the experimental model of animals [25]. According to the data from previous research, feeding rats with HFD can promote the development of insulin resistance in the experimental model. STZ injections at very high doses have been shown to critically damage pancreatic $\beta$-cell functioning, leading to insulin secretion, which is considered that it resembles T1DM. Recently, HFD- and low-dose injections of STZ have been reported to damage $\beta$-cell functioning very less and induce a gradual impairment of insulin secretion, which is similar to the natural progression of T2DM in humans. Therefore, in the current study, HFD and low-dose of STZ (35 mg/kg BW) were adopted to develop T2D in albino Wistar rats [26].

From the OGTT data, it is clear that administration of POH at the dose $50 \mathrm{mg} / \mathrm{kg}$ and $100 \mathrm{mg} / \mathrm{kg}$ effectively prevented the increase in plasma glucose level without causing hypoglycemia in rats as efficiently as the

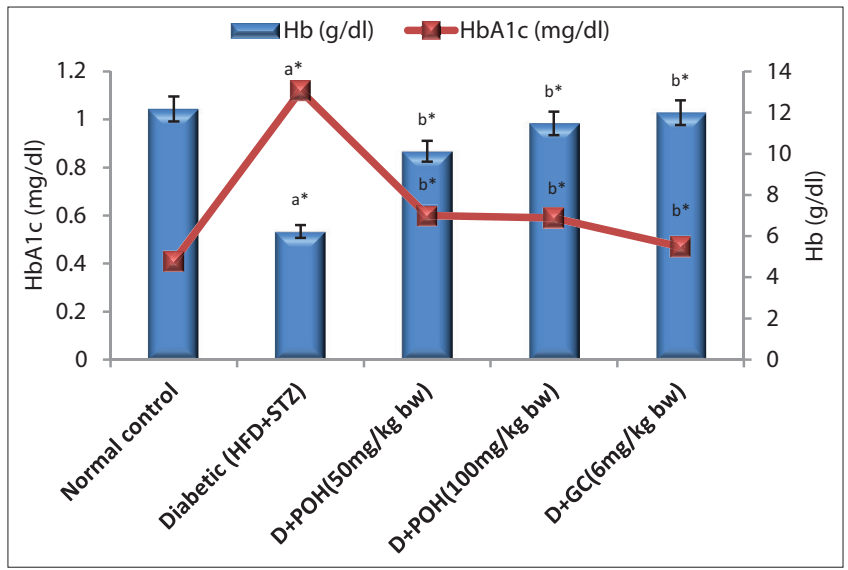

Fig. 6: Effect of Perillyl alcohol on hemoglobin and glycosylated hemoglobin levels of normal control and diabetic treated rats.

Bars are expressed as means \pm standard deviation for six rats in each group. One-way ANOVA followed by Duncan's multiple

range test. Statistical significance was compared within the

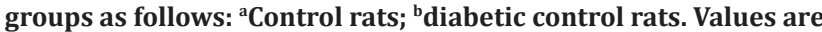
statistically significant at ${ }^{*} \mathbf{p}<0.05$

reference drug glibenclamide. This result of OGTT confirms that the reduction of intestinal glucose transporter is similar to the finding [27]. Treatment with HFD and low dose of STZ (35 mg/kg)-induced diabetic rats started reducing FBG levels in a dose-dependent manner after 10 days, 20 days, and made them normoglycemic after 30 days. The antihyperglycemic effect of $\mathrm{POH}$ at the dose of $50 \mathrm{mg} / \mathrm{kg}$ and $100 \mathrm{mg} / \mathrm{kg}$ was found to be comparable to the effect exerted by the reference drug glibenclamide at a dose of $6 \mathrm{mg} / \mathrm{kg}$ BW.

DM is associated with loss of BW, polyuria (frequent urination), polydipsia (frequent thirst), and polyphagia (frequent hunger) [28]. In T2DM energy metabolism in liver tissue is impaired that enables low energy state to stimulate satiety center that in turn increases food intake [29]. That means hepatic energy has an effect on feeding behavior that regulates BW [30]. Initially, rats that were fed with HFD for a period of 4 weeks showed rapid increase in BW due to its deposition in several body fat pads [31]

The weight gain was significantly reduced in diabetic rats; however, the food intake was more during the experiment this is due to poor glycemic control, and carbohydrate energy source was not available and results in excessive catabolism of proteins to provide amino acids for gluconeogenesis leading to muscle waste and weight loss during insulin deficiency in diabetic rats [32]. Osmotic diuresis increases fluid intake in diabetic rats when compared to normal control rats. Treatment of rats with $\mathrm{POH}$ at $50 \mathrm{mg} / \mathrm{kg} \mathrm{BW}$ and $100 \mathrm{mg} / \mathrm{kg} \mathrm{BW}$ significantly shows improvement in glycemic control in diabetic treated rats by improving BW decreasing food intake and fluid intake. Higher glucose levels result in non-enzymatic glycation of proteins which also include $\mathrm{Hb}$ and the crystalline protein of lens. Glycosylation of hemoglobin occurs in uncontrolled diabetes, and non-enzymatic glycation of proteins increase is directly proportional to the FBG levels [33]. According to 


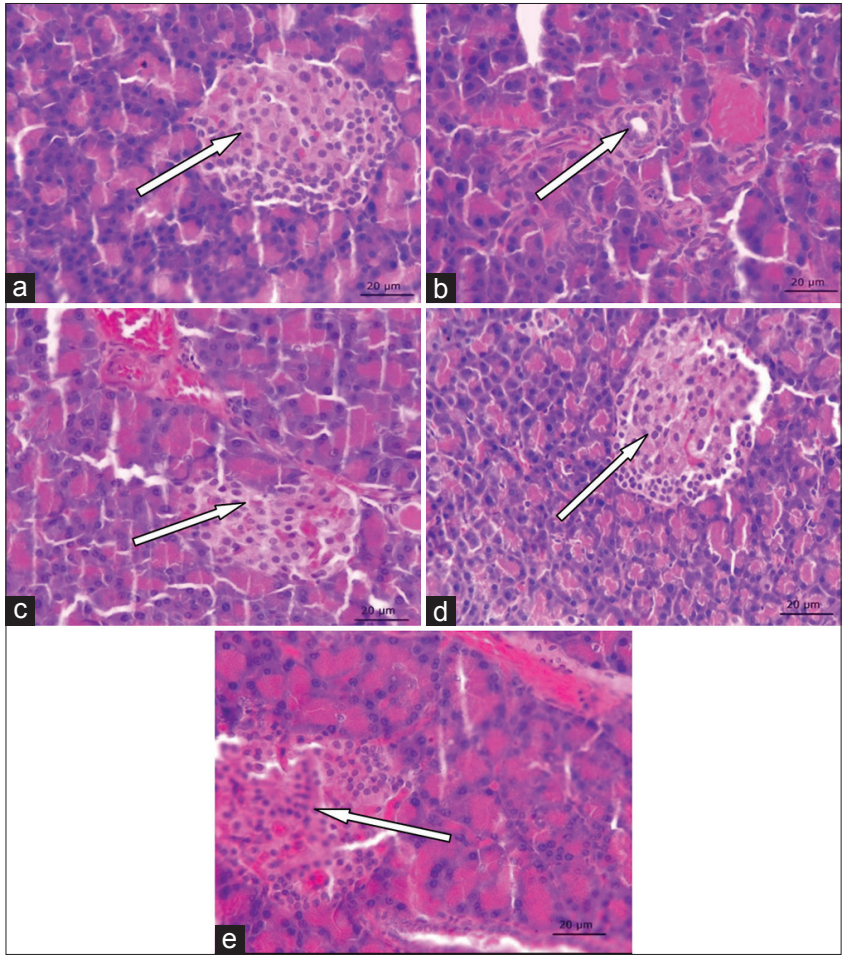

Fig. 7: (a-e) Histopathological observations of Perillyl alcohol $(\mathrm{POH})$ and glibenclamide treated pancreas in high-fat diet low-dose streptozotocin-induced diabetic rats after 30 days of treatment (Hematoxylin and Eosin staining). (a) Normal control - presence of normal pancreatic islet cells; (b) diabetic control - reduction in the size of islets, damaged $\beta$-cell population and extensive necrotic changes followed by fibrosis and atrophy; (c and d) diabetic+POH $50 \mathrm{mg} / \mathrm{kg}$ and $100 \mathrm{mg} / \mathrm{kg}$ body weight (BW) - restored necrotic and fibrotic changes and increased number and size of the islets; (e) Diabetic+Glibenclamide $6 \mathrm{mg}$ / $\mathrm{kg} \mathrm{BW}$ ) - absence of necrosis and Fibrotic changes, increased number and size of the islets

the study of UKPDS, the continued increase of HbA1c leads to steady decline in beta cell function [34].

The increase in HbA1c observed in the diabetic rats relative to the normal control may be attributed to the higher rate of glycation of hemoglobin under the hyperglycemic condition resulting from HFD/ STZ administration. Administration of $\mathrm{POH}$ decreased glucose and increased $\mathrm{Hb}$ levels that led to a reduction in the HbA1c levels in diabetic rats when compared to the diabetic control group. Reports have shown that agents with antioxidant and free radical scavenging properties significantly inhibit protein glycation reactions associated with DM [35] This further supports the antidiabetic effect of POH.

Reflection of insulin activity depends on the quantity of glycogen in hepatic and skeletal muscle tissue; glycogen is the storable form of glucose. The synthesis and degradation of glycogen which is a storable form of glucose are considered as reciprocally regulated pathways in the body. Under physiological conditions, insulin stimulates glycogen synthase and inhibits glycogen phosphorylase activities and deposits glycogen in cells [36]. This regulatory function of insulin is compromised in diabetic rats that account for depleted hepatic glycogen level observed in this study. Oral administration of $\mathrm{POH}$ at the dose of 50 and $100 \mathrm{mg} / \mathrm{kg} \mathrm{BW}$ brought back glycogen levels near toward normal level, and this is achieved by increasing the pancreatic secretion of insulin in diabetic treated rats. Our results are in harmony with Jayanthy and Subramanian [37] who reported that rosmarinic acid regulated glycogen metabolizing enzymes in HFD/STZ-induced experimental diabetic rats. Administration of HFD/ STZ resulted in significant increase in plasma glucose levels with a decline

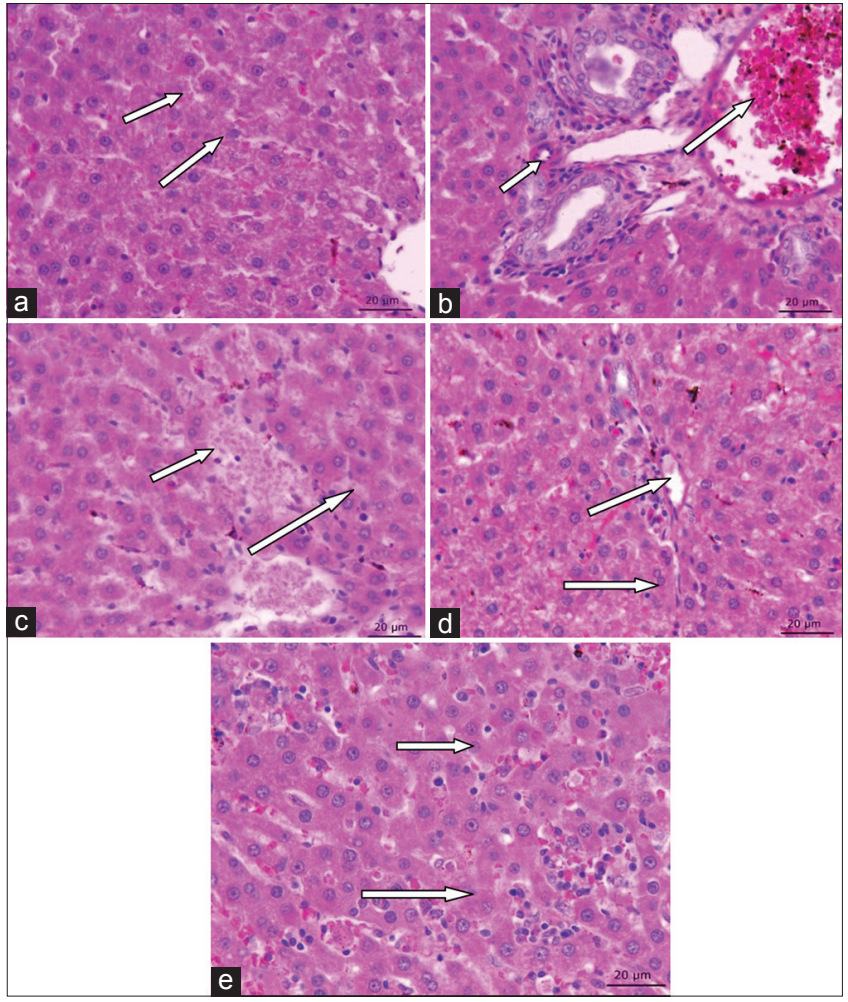

Fig. 8: (a-e) Histopathological observations of Perillyl alcohol $(\mathrm{POH})$ and glibenclamide treated liver in high-fat diet streptozotocin-induced diabetic rats after 30 days of treatment (Hematoxylin and Eosin staining, $\times 40$ ). (a) Normal control normal histological structure of hepatic, hepatic cords, hepatic sinusoids, and central vein. (b) Diabetic control - mild sinusoids damaged hepatocytes were observed. (c) Diabetic+POH $50 \mathrm{mg} / \mathrm{kg}$

body weight (BW), (d) Diabetic+POH $100 \mathrm{mg} / \mathrm{kg} \mathrm{BW}$, and

(e) Diabetic+Glibenclamide $6 \mathrm{mg} / \mathrm{kg} \mathrm{b} \mathrm{BW}$ ) - showed reversible tissue regeneration and prominent hepatocytes

in compensatory insulin release resulting from impaired $\beta$-cell function [38]. As pancreatic $\beta$-cells functions within a narrow range of plasma glucose, several fold increase in $\beta$-cell apoptosis with a critical decline in $\beta$-cell mass occurs on exposure to elevated glucose levels. The severity of $\beta$-cell failure depends on the progenitor's metabolic state during HFD administration [39]. In this research, we observed reduction in plasma insulin and increase in glucose levels in the plasma of HFD low-dose STZinduced diabetes in Wistar rats. When rats were treated orally with $\mathrm{POH}$ $50 \mathrm{mg} / \mathrm{kg} \mathrm{BW}$ and $100 \mathrm{mg} / \mathrm{kg} \mathrm{BW}$ improved insulin secretion and decrease glucose levels in diabetic treated rats; $\mathrm{POH}$ treatment increased the number of functioning beta cells and improved insulin secretion which is evidenced in histological studies. Thus, POH significantly improved insulin secretion and decreased glycemic levels in diabetic treated rats.

\section{CONCLUSION}

The current study clearly demonstrates that daily administration of POH exhibited a pronounced hypoglycemic effect. These results suggest a promising effect in intestinal glucose transport, $\mathrm{HbA1c}, \mathrm{Hb}$, liver, and muscle glycogen, BW, fluid intake and also improve the histology of pancreas and liver. In future, if these data will be validated in clinical trials, $\mathrm{POH}$ seems to offer potential as a plant terpene that is useful for alleviating metabolic syndrome.

\section{ACKNOWLEDGMENT}

All the authors would like to thank the Department of Zoology, Annamalai University Annamalai Nagar, Tamil Nadu, India, for providing all facilities for this work. 


\section{AUTHORS' CONTRIBUTIONS}

Towseef Hassan and Insha Naseer, Ph. D Research Scholars performed the experimental work, prepared the data, and drafted the write-up. C. Elanchezhiyan, Professor, Department of Zoology guided the research work and edited the write-up.

\section{CONFILICTS OF INTEREST}

There are no conflicts of interest.

\section{REFERENCES}

1. Bagri PR, Ali MO, Aeri VI, Bhowmik MA. Isolation and antidiabetic activity of new lanostenoids from the leaves of Psidium guajava L. Int J Pharm Pharm Sci 2016;8:14-8.

2. International Diabetes Federation. IDF Diabetes Atlas. $7^{\text {th }}$ ed. Belgium: International Diabetes Federation; 2017.

3. Hruby A, Hu FB. The epidemiology of obesity: A Big picture. Pharmacoeconomics 2015;33:673-89.

4. Chandirasegaran G, Elanchezhiyan C, Ghosh K, Sethupathy S. Berberine chloride ameliorates oxidative stress, inflammation and apoptosis in the pancreas of streptozotocin induced diabetic rats. Biomed Pharmacother 2017;95:175-85.

5. Golay A, Ybarra J. Link between obesity and Type 2 diabetes. Best Pract Res Clin Endocrinol Metab 2005;19:649-63.

6. Pal S, Gautam S, MishraA, Maurya R, SrivastavaAK.Antihyperglycemic and antidyslipidemic potential of Ipomoea batatas leaves in validated diabetic animal models. Int J Pharm Pharm Sci 2015;7:176-86.

7. Naziroğlu M, Butterworth PJ. Protective effects of moderate exercise with dietary Vitamin $\mathrm{C}$ and $\mathrm{E}$ on blood antioxidative defense mechanism in rats with streptozotocin-induced diabetes. Can J Appl Physiol 2005;30:172-85.

8. Chanwitheesuk A, Teerawutgulrag A, Rakariyatham N. Screening of antioxidant activity and antioxidant compounds of some edible plants of Thailand. Food Chem 2005;92:491-7.

9. Rahimi R, Nikfar S, Larijani B, Abdollahi M. A review on the role of antioxidants in the management of diabetes and its complications. Biomed Pharmacother 2005;59:365-73.

10. Belanger JT. Perillyl alcohol: Applications in oncology. Altern Med Rev 1998;3:448-57.

11. Ansari MA, Fatima Z, Hameed S. Anticandidal effect and mechanisms of monoterpenoid, perillyl alcohol against Candida albicans. PLoS One 2016;11:e0162465.

12. Bailey HH, Attia S, Love RR, Fass T, Chappell R, Tutsch K, et al. Phase II trial of daily oral perillyl alcohol (NSC 641066) in treatmentrefractory metastatic breast cancer. Cancer Chemother Pharmacol 2008;62:149-57.

13. Bhatia SP, McGinty D, Letizia CS, Api AM. Fragrance material review on p-mentha-1,8-dien-7-ol. Food Chem Toxicol 2008;46 Suppl 11:S197-200.

14. Laszlo P. Citrus: A History. Chicago, Illinois: University of Chicago Press; 2007.

15. Food Additives Permitted for Direct Addition to Food for Human Consumption. In: US Food and Drug Administration, 21CFR172.515, Code of Federal Regulations Title 21. Available from: https://www.accessdata.fda.gov/scripts/cdrh/cfdocs/cfcfr/CFRSearch. $\mathrm{cfm} ? \mathrm{FR}=172.515$. [Last accessed on $2014 \mathrm{Apr} 01$ ]

16. Magdalena JS, Flaczyk E, Jeszka J, Krejpcio Z, Król E, Buchowski MS. Mulberry leaf extract intake reduces hyperglycaemia in streptozotocin (STZ)-induced diabetic rats fed high-fat diet. J Funct Foods 2014;1:9-17.

17. Veerapur VP, Prabhakar KR, Kandadi MR, Srinivasan KK, Unnikrishnan MK. Antidiabetic effect of Dodonaea viscosa aerial parts in high fat diet and low dose streptozotocin-induced Type 2 diabetic rats: A mechanistic approach. Pharm Biol 2010;48:1137-48.

18. Salahuddin M, Jalalpure SS. Antidiabetic activity of aqueous fruit extract of Cucumis trigonus Roxb. In streptozotocin-induced-diabetic rats. J Ethnopharmacol 2010;127:565-7.

19. Luna LG. Manual of Histologic Staining Methods of the Armed Forces Institute of Pathology. $3^{\text {rd }}$ ed. New York: McGraw Hill; 1968.

20. Bhandari U, Chaudhari HS, Khanna G, Najmi AK. Antidiabetic effects of Embelia ribes extract in high fat diet and low dose streptozotocininduced Type 2 diabetic rats. Front Life Sci 2013;7:186-96.

21. Trinder P. Determination of glucose in blood using glucose oxidase with an alternative oxygen acceptor. Ann Clin Biochem 1969;6:24-7.

22. Drabkin DL, Austin JM. Spectrophotometric constants for common $\mathrm{Hb}$ derivatives in human, dog and rabbit blood. J Biol Chem 1932;98:719-33.

23. Bannon P. Effect of $\mathrm{pH}$ on the elimination of the labile fraction of glycosylated hemoglobin. Clin Chem 1982;28:2183.

24. Morales MA, Jabbay AJ, Tenenzi HP. Mutation affecting accumulation of glycogen. Neurospora Newslet 1973;20:24-5.

25. Prabu M, Kumuthakalavalli R. Antidiabetic potential of the oyster mushroom Pleurotus florida (Mont.) singer. Int J Curr Pharm Res 2017;9:51-4

26. Qian C, Zhu C, Yu W, Jiang X, Zhang F. Highfat diet/lowdose streptozotocin induced Type 2 diabetes in rats impacts osteogenesis and wnt signaling in bone marrow stromal Cells. PLoS One 2015;10:e23568.

27. Das S, Bhattacharya S, Prasanna A, Kumar RB, Pramanik G, Haldar PK, et al. Preclinical evaluation of antihyperglycemic activity of Clerodendron infortunatum leaf against streptozotocin-induced diabetic rats. Diabetes Ther 2011;2:92-100.

28. Chandirasegaran G, Elanchezhiyan C, Ghosh K, Sethupathy S. Efficacy of berberine chloride on hyperglycemic in streptozotocin induced diabetic rats. Int Res J Pharm 2016;7:14-8.

29. Cooper ME, Regnell SE. The hepatic cannabinoid 1 receptor as a modulator of hepatic energy state and food intake. Br J Clin Pharmacol 2014;77:21-30.

30. Friedman MI. Obesity and the hepatic control of feeding behavior. Drug News Perspect 2007;20:573-8.

31. Hassan T, Elanchezhiyan C, Naseer I, Veerakumar D. Protective effect of perillyl alcohol $(\mathrm{POH})$ a monoterpene: On high fat diet induced hyperlipidemia in albino Wistar rats a preliminary study. Int J Pharm Sci Res 2019;10:1000-4.

32. Panigrahi G, Panda C, Patra A. Extract of Sesbania grandiflora ameliorates hyperglycemia in high fat diet-streptozotocin induced experimental diabetes mellitus. Scientifica (Cairo) 2016;2016:4083568.

33. Madhuri K, Naik PR. Ameliorative effect of borneol, a natural bicyclic monoterpene against hyperglycemia, hyperlipidemia and oxidative stress in streptozotocin-induced diabetic wistar rats. Biomed Pharmacother 2017;96:336-47.

34. Turner RC, Cull CA, Frighi V, Holman RR. Glycemic control with diet, sulfonylurea, metformin, or insulin in patients with Type 2 diabetes mellitus: Progressive requirement for multiple therapies (UKPDS 49). UK prospective diabetes study (UKPDS) group. JAMA 1999;281:2005-12.

35. Ujilestari T, Ariyadi B, Martien R, Zuprizal, Dono N. Optimization of self-nano emulsifying drug delivery systems of lemongrass (Cymbopogon citrates) essential oil. Int J Appl Pharm 2019;11:144-9.

36. Pederson BA, Schroeder JM, Parker GE, Smith MW, DePaoli-Roach AA, Roach PJ, et al. Glucose metabolism in mice lacking muscle glycogen synthase. Diabetes 2005;54:3466-73.

37. Jayanthy G, Subramanian S. Rosmarinic acid, a polyphenol, ameliorates hyperglycemia by regulating the key enzymes of carbohydrate metabolism in high fat diet STZ induced experimental diabetes mellitus. Biomed Prev Nutr 2014;4:431-7.

38. Antony PJ, Gandhi GR, Stalin A, Balakrishna K, Toppo E, Sivasankaran K, et al. Myoinositol ameliorates high-fat diet and streptozotocin-induced diabetes in rats through promoting insulin receptor signaling. Biomed Pharmacother 2017;88:1098-113.

39. Cerf ME. High fat programming of beta-cell failure. Adv Exp Med Biol 2010;654:77-89. 